\title{
Epidemiological patterns of cervical human papillomavirus infection among women presenting for cervical cancer screening in North-Eastern Nigeria
}

Mohammed Mohammed Manga ${ }^{1 *}$, Adeola Fowotade ${ }^{2}$, Yusuf Mohammed Abdullahi ${ }^{3}$, Aliyu Usman El-nafaty ${ }^{4}$, Danladi Bojude Adamu ${ }^{5}$, Hamidu Umar Pindiga ${ }^{3}$, Rasheed Ajani Bakare ${ }^{2}$ and Abimbola Olu Osoba ${ }^{2}$

\begin{abstract}
Background: Sub-Saharan countries including Nigeria have the highest burden of Human Papillomavirus (HPV) infection in the world. Most studies on HPV surveillance in Nigeria were done in the southern part of the country. Geographical and socio-cultural diversity of Nigeria makes these data unlikely to be universally representative for the entire country. Northern Nigeria especially the North-East carries a higher prevalence of cervical cancer and many of its risk factors. The region may be harbouring a higher prevalence of HPV infection with a possibility of different genotypic distribution. This study was carried out to determine the burden and confirm the predominant HPV genotypes among women presenting for cervical cancer screening at the Federal Teaching Hospital Gombe (FTHG), North-eastern, Nigeria.
\end{abstract}

Methods: The study was an observational hospital based cross sectional study among women who presented for cervical cancer screening in FTHG. A total of 209 consenting women were tested for cervical HPV infection using PCR. DNA sequencing was carried out on positive samples to determine the prevalent HPV genotypes.

Results: The prevalence of cervical HPV infection among the participants with mean age of $39.6 \pm 10.4$ years was $48.1 \%$. The five most predominant genotypes were $18,16,33,31$ and 35 , with prevalence of $44.7 \%, 13.2 \%, 7.9 \%, 5.3 \%$ and $5.3 \%$ respectively. Other genotypes observed were 38, 45, 56, 58, 82 and KC5. Multiple HPV infections were detected among $7.9 \%$ of participants. Risk factors such as level of education $\left(X^{2}=15.897 ; p=0.007\right)$, age at sexual debut $\left(X^{2}=6.916 ; p=0.009\right)$, parity $\left(X^{2}=23.767 ; p=0.000\right)$, number of life time sexual partners $\left(X^{2}=7.805 ; p=0.005\right)$, age at first pregnancy $\left(X^{2}=10.554 ; p=0.005\right)$ and history of other malignancies $\left(X^{2}=7.325 ; p=0.007\right)$ were found to have a statistically significant association with HPV infection.

Conclusion: This study identified a high burden of HPV infection in Northern Nigeria while also confirming HPV 18 and 16 as the most predominant genotypes. It further justifies the potential benefit of the currently available HPV vaccines in the area. A larger and community based study is however recommended for better representation of the area.

Keywords: Human Papillomavirus, Genotypes, Cervix, Women, Nigeria

\footnotetext{
* Correspondence: mangamuhammad@yahoo.co.uk

${ }^{1}$ Department of Medical Microbiology and Immunology, Federal Teaching

Hospital Gombe, Gombe, Gombe state Nigeria

Full list of author information is available at the end of the article
} 


\section{Introduction}

Among the approximately 200 known HPV types, about 40 can infect the cervix out of which 13 types $(16,18$, $31,33,35,39,45,51,52,56,58,59$ and 66) from among the alpha species have been classified as group 1 carcinogens [1-3]. Of these oncogenic viruses, HPV-16 and HPV-18 are the most prevalent worldwide. They have been associated with about $70 \%$ of invasive cervical cancer (ICC) worldwide and about $50 \%$ of cervical intraepithelial neoplasia grade 3 (CIN3) [1, 4]. Aetiologically, Five HPV types $(16,18,31,33$, and 45$)$ have been linked to $80 \%$ of cervical cancers while the other types contribute the remaining $20 \%$ [5]. The high-risk HPV (hr-HPV) types are also implicated in vulvar, vaginal, penile, anal, and oropharyngeal neoplasms [5]. Infection of the genital tract with HPV is considered the most common sexually transmitted infection worldwide [5]. Several HPV genotypes tend to be transmitted together, leading to a high proportion (20-30\%) of concurrent infections with different types [1].

Worldwide the incidence and prevalence of HPV peaks at younger age soon after the start of sexual activity below the age of 25-35 years but subsequently declines with infections clearing as the infected individual grows older $[5,6]$. Globally, age-adjusted prevalence of HPV in women with normal cytology is estimated at $10.4 \%$, ranging from $8.1 \%$ in Europe to $22.1 \%$ in Africa [5].

Persistent HPV infection of the cervical epithelium is the major risk factor for cervical cancer as more than $99 \%$ of cases contain hr-HPV. Early/polygamous marriages [7], high parity, tobacco smoking, long-term hormonal contraceptive use, co-infection with Chlamydia trachomatis, herpes simplex virus type 2, HIV, immunosuppression, certain dietary deficiencies, genetic and immunological host factors have been observed to be major contributory factors to cervical cancer [8]. Other risk factors for cervical cancer include imbalanced vaginal flora, having an uncircumcised male partner and low socio-economic status [5, 9].

Cervical cancer is the second most common cancer in women worldwide and a leading cause of cancer deaths in developing countries [7]. The prevalence of cervical infection with HPV particularly high risk types that cause cervical cancer varies greatly worldwide [10].

Despite being among the areas with highest prevalence in the world, awareness about HPV and its association with cervical cancer is still poor in Nigeria [11]. The North-East zone of Nigeria has the highest poverty rates in the country [12]. Socio-cultural practices in the region also encourages early marriage and polygamy [13]. Despite cervical cancer being the commonest genital tract malignancy in this region (70.5\%), only $11.5 \%$ of women ever had a Pap smear with very poor knowledge of HPV vaccine even among healthcare workers $[14,15]$.

In this study we determined the prevalence of HPV and its associated risk factors among women presenting for cervical cancer screening in Gombe, North-eastern Nigeria.

\section{Materials and methods}

\section{Study area and population}

The study was carried out among 209 women who presented for cervical cancer screening between August 2013 and May 2014 at the FTH Gombe. However, the screening for many of the participants was based on referral following risk assessment by healthcare staff. Ethical approval was obtained from Research and Ethics Committee of FTH Gombe. Recruited women were counselled and all those who gave informed consent were enrolled into the study.

\section{Specimen collection and storage}

Rovers $^{\circ}$ Cervex-Brush ${ }^{\circ}$ cell sampling device (Rovers Medical Devices B.V 5347 KV Oss, The Netherlands) was used for specimen collection. Specimen was obtained by inserting the cytobrush into the cervical canal and rotating it four times in a clockwise direction to collect all the cervical epithelial cells which adhered to the flat sides of the bristles.

The brush was then inserted into the vial containing preservative fluid. Liquid-based cytology system (LiquiPREP by LGM International, Inc, Melbourne, FL, USA) for collection and transport of cervical specimen was used.

\section{DNA extraction}

DNA from exfoliated cervical cells collected in the preservative fluid (Liqui-PREP) was extracted using proteinase $\mathrm{K}$ digestion, followed by phenol-chloroform extraction and ethanol precipitation. Gel extraction prior to DNA cleaning/purification for sequencing was done using QIAquick Gel Extraction Kit (QIAGEN Sample \& Assay Technologies, Germany).

\section{Detection and typing of HPV}

All the cervical specimens were tested for the presence of oncogenic HPV DNA using a nested Polymerase Chain Reaction (nPCR) with GP5+/GP6+ (GP5+ [5' TTTGTTACTGTGGTAGATACTAC-3'] and GP6+ [5' - GAAAAATAAACTGTAAATCATATTC-3']) [16] and PGMY 09/11 [17] consensus primers which amplifies a $150 \mathrm{bp}$ fragment of the L1 HPV genomic region. AccuPower HotStart Premix (Bioneer Corporation, South Korea) was used for the PCR. Genotypic identification was achieved by direct sequencing using the Gp $6+$ oligoprimer. Thermal cycler (Bio Rad) and Sequencing machine 
(Beckman Coultier CEQ 2000XL) were used for PCR and sequencing respectively. Sequence alignments were performed against various standard HPV genotype sequences stored in the GenBank database by on-line BLAST analysis to arrive at specific genotyping. The procedures were carried at the DNA Labs, Kaduna, Nigeria.

\section{Data analysis}

Descriptive and inferential statistical analysis of the data was done using Statistical Package for the Social Sciences version 22 (SPSS Inc., Illinios, USA). Student's $t$ test was used to compare means for continuous variables, while categorical variables were summarized as proportions and further analyzed using Chi square to assess association between them. A logistic regression was performed to ascertain the effects of variables which showed a statistically significant association with HPV testing based on Chi square. Figures and tables were appropriately used in representing the analyzed data (Additonal file 1).

\section{Results}

Socio-demographic characteristics and HPV infection

Table 1 showed the association between sociodemographic characteristics of the participants and HPV infection. A total of two hundred and nine women participated in the study with their mean age being 39.6 years and standard deviation (SD) of \pm 10.4 years. Majority 127 (61.2\%) were between the ages of 30 and 45 years with only $36(17.2 \%)$ and $45(21.5 \%)$ being below 30 years and above 45 years respectively. The mean age of women found to be positive for HPV was $40.79( \pm 11.23)$ years compared to $38.49( \pm 9.47)$ years among those with no HPV infection. Student $t$ test showed no statistically significant difference between the mean ages $(P=0.111)$.

More than half, 110 (53.4 \%) were educated up to tertiary level with only 32 (15.4\%) having no formal education while $14(6.7 \%)$ and $51(24.5 \%)$ had primary and secondary education respectively. Nearly all, 182 (88.0 \%) were married as both single and divorced women accounted for only $3.8 \%$ each while $4.3 \%$ were widows. Majority, 128 (64.8\%) of the women were from monogamous family settings. Less than half, 99 (48.1\%) were employed (government and private) with all the remaining 108 (51.9\%) being unemployed among which house wives were predominant. Muslims were slightly more 118 (56.5 \%) than Christians 90 (43.5\%).

Except for level of education, other socio-demographic characteristics did not show any statistically significant association with HPV infection.

\section{Analysis of HPV infection}

HPV DNA was detected in 100 (48.1\%) of the participants while $108(51.9 \%)$ were negative for the virus.
Overall, ten different HPV types were identified from this study. HPV types 18 and 16 were the most predominant with proportions of $44.7 \%$ and $13.2 \%$ respectively. Multiple HPV infections were identified among $7.9 \%$ of the specimens. Other genotypes identified were types 31 , $33,35,38,45,56,58,82$ and KC5 with corresponding proportions of $5.3 \%, 7.9 \%, 2.6 \%, 2.6 \%, 2.6 \%, 2.6 \%$, $2.6 \%, 5.3 \%$ and $2.6 \%$ respectively. Of the 209 participants, normal cytological findings were observed among 126 (61.6 \%) while $80(39.0 \%)$ had abnormal features and $3(1.4 \%)$ had unsatisfactory smears for cytologic studies. Figure 1 shows the percentage distribution of the different cytological findings in comparison with corresponding HPV types.

\section{Risk factors for HPV infection}

Table 2 showed the association between HPV infection and some risk factors within the participants. Of the 67 participants who had early sexual debut (earlier than 18 years of age), 41 (61.2\%) were positive for HPV DNA as against $57(41.6 \%)$ of the respondents who started their sexual life at or later than 18 years of age. Early sexual debut showed a statistically significant association with HPV infection $\left(X^{2}=6.916, P=0.009\right)$. Multiple life time sexual partners also conferred a significant risk for HPV infection $\left(X^{2}=7.805, P=0.005\right)$ as $26(68.4 \%)$ out of the 38 respondents with multiple sexual partners were HPV positive compared to 71 (43.3\%) out of 164 with single life time sexual partner. Statistically significant association was also observed between ages at first pregnancy (primigravidity) and HPV infection $\left(X^{2}=10.554\right.$, $P=0.005)$ as respondents with history of early pregnancy (less than 18 years) showed higher percentage of HPV infection (75.0 \%) in comparison to $43.7 \%$ and $42.9 \%$ for normal and late age of primigravidity respectively. Parity of the participants also showed a statistically significant association with HPV infection $\left(X^{2}=23.767, P=<0.001\right)$ with grand multiparous and great grand multiparous women showing a higher percentage of infection; $62.3 \%$ and $80 \%$ respectively. Although women in a polygamous family setting showed higher proportion of HPV infection than those in monogamous setting, the association was not statistically significant $\left(X^{2}=1.517, P=0.468\right)$. Family history of cervical cancer did not reveal a significant association with HPV infection $\left(X^{2}=0.719, P=0.397\right)$ but history of other malignancies had a statistically significant association with HPV infection $\left(X^{2}=7.325, P=0.007\right)$. Among those with history of other malignancies, the type of malignancy (gynaecologic or others) did not show a statistically significant association with HPV infection $\left(X^{2}=0.522, P=0.470\right)$.

Other factors as participants' HIV status, partners' use of condom and use of hormonal contraceptives did not show statistically significant association with 
Table 1 Association between socio-demographic factors and HPV infection

\begin{tabular}{|c|c|c|c|c|c|}
\hline \multirow[b]{2}{*}{ Age group (years) } & \multicolumn{2}{|c|}{ Presence of HPV DNA } & \multirow[t]{2}{*}{ Total } & \multirow[t]{2}{*}{$x^{2}$} & \multirow[t]{2}{*}{$P$ value } \\
\hline & $\begin{array}{l}\text { Positive N } \\
(\%)\end{array}$ & $\begin{array}{l}\text { Negative N } \\
(\%)\end{array}$ & & & \\
\hline$<30$ & $17(17.0 \%)$ & 19 (17.6\%) & 036 & 0.642 & 0.725 \\
\hline $30-45$ & $59(59.0 \%)$ & $68(63.0 \%)$ & 127 & & \\
\hline$>45$ & $24(24.0 \%)$ & $21(19.4 \%)$ & 045 & & \\
\hline Total & $100(100 \%)$ & $108(100 \%)$ & 208 & & \\
\hline \multicolumn{6}{|l|}{ Type of Family } \\
\hline Monogamous & $59(61.5 \%)$ & $69(67.6 \%)$ & 128 & 0.829 & 0.363 \\
\hline Polygamous & 37 (38.5 \%) & $33(32.4 \%)$ & 070 & & \\
\hline Total & 96 (100\%) & $102(100 \%)$ & 198 & & \\
\hline \multicolumn{6}{|l|}{ Level of Education } \\
\hline $\begin{array}{l}\text { No formal } \\
\text { education }\end{array}$ & $15(15.0 \%)$ & 17 (15.9\%) & 032 & 15.897 & $0.007^{*}$ \\
\hline Primary & $10(10.0 \%)$ & $04(03.7 \%)$ & 014 & & \\
\hline Secondary & $24(24.0 \%)$ & $27(25.2 \%)$ & 051 & & \\
\hline OND/NCE/HND & $40(40.0 \%)$ & 33 (30.8 \%) & 073 & & \\
\hline $\begin{array}{l}\text { University } \\
\text { graduate }\end{array}$ & 05 (05.0 \%) & $23(21.5 \%)$ & 028 & & \\
\hline Others & 06 (06.0 \%) & $03(02.8 \%)$ & 009 & & \\
\hline Total & $100(100 \%)$ & $107(100 \%)$ & 207 & & \\
\hline \multicolumn{6}{|l|}{ Marital Status } \\
\hline Married & $88(88.0 \%)$ & $94(87.9 \%)$ & 182 & 1.963 & 0.580 \\
\hline Single & $03(03.0 \%)$ & 05 (04.7\%) & 008 & & \\
\hline Divorced & 03 (03.0 \%) & 05 (04.7\%) & 008 & & \\
\hline Widow & 06 (06.0 \%) & $03(02.8 \%)$ & 009 & & \\
\hline Total & 100 (100\%) & 107 (100\%) & 207 & & \\
\hline \multicolumn{6}{|l|}{ Employment Status } \\
\hline Employed & 47 (47.0 \%) & $52(48.6 \%)$ & 099 & 0.053 & 0.818 \\
\hline Unemployed & $53(53.0 \%)$ & 55 (51.4\%) & 108 & & \\
\hline Total & $100(100 \%)$ & 107 (100\%) & 207 & & \\
\hline \multicolumn{6}{|l|}{ Religion } \\
\hline Islam & $53(44.9 \%)$ & 65 (60.2 \%) & 118 & 1.092 & 0.296 \\
\hline Christianity & 47 (52.2 \%) & 43 (38.8 \%) & 090 & & \\
\hline Total & $100(100 \%)$ & 108 (100\%) & 208 & & \\
\hline \multicolumn{6}{|l|}{ Residence } \\
\hline $\begin{array}{l}\text { Within Gombe } \\
\text { city }\end{array}$ & 75 (75.0 \%) & 87 (81.3 \%) & 162 & 1.260 & 0.533 \\
\hline Other LGAs & $18(18.0 \%)$ & 15 (14.0\%) & 033 & & \\
\hline $\begin{array}{l}\text { Outside Gombe } \\
\text { state }\end{array}$ & 07 (07.0 \%) & 05 (04.7\%) & 012 & & \\
\hline Total & 100 (100 \%) & $107(100 \%)$ & 207 & & \\
\hline \multicolumn{6}{|l|}{ Tribe } \\
\hline Fulani & $28(28.0 \%)$ & 29 (27.1\%) & 057 & 3.345 & 0.341 \\
\hline Tangale & 26 (26.0\%) & 18 (16.8\%) & 044 & & \\
\hline
\end{tabular}

Table 1 Association between socio-demographic factors and HPV infection (Continued)

\begin{tabular}{llllll}
\hline Hausa & $11(11.0 \%)$ & $17(15.9 \%)$ & 028 & & \\
Others & $35(35.0 \%)$ & $43(40.2 \%)$ & 078 & & \\
Total & $100(100 \%)$ & $107(100 \%)$ & 207 & & \\
Type of housing & & & & & \\
Personal house & $50(50.0 \%)$ & $63(58.9 \%)$ & 113 & 6.023 & 0.197 \\
Rented flats & $27(27.0 \%)$ & $32(29.9 \%)$ & 059 & & \\
Self contained & $20(20.0 \%)$ & $10(09.3 \%)$ & 030 & & \\
Single rooms & $02(02.0 \%)$ & $02(01.9 \%)$ & 004 & \\
Others & $01(01.0 \%)$ & $00(00.0 \%)$ & 001 & \\
Total & $100(100 \%)$ & $107(100 \%)$ & 207 & \\
\hline
\end{tabular}

* = statistically significant (i.e. <0.05), OND (Ordinary National Diploma), HND (Higher National Diploma), NCE (National Certificate of Education), LGA (Local Government Area)

HPV infection. Although not shown in any of the tables, history suggestive of genital tract infection (vaginal discharge, dyspareunia and vaginal bleeding), history of alcohol consumption and cigarette smoking did not show statistical significance in associated with HPV infection. Partners' circumcision status could not be analyzed as all respondents had circumcised sexual partners.

Logistic regression was performed to ascertain the effects of level of education, age at sexual debut, parity, number of sexual partners age at primigravidity and history of other malignancies on the likelihood that participants have HPV infection (Table 3).

\section{Discussion}

This study reveals a $48.1 \%$ prevalence of cervical HPV infection among women who presented for cervical cancer screening in Gombe, north-eastern Nigeria. It is one of the highest prevalence rates among one of the oldest studied populations (mean age of $39.6 \pm 10.4$ years) to be ever reported from any part of Nigeria and the first from North-Eastern Nigeria [6, 10, 11, 18-20]. Although there are only a few studies from Northern Nigeria, a high prevalence of $76 \%$ reported from Kano further highlights the possibility of this region carrying the highest HPV burden in the country [18].

Several Nigerian studies among diverse population groups had reported lower prevalence rates including $19.6 \%$ among HIV infected patients in Lagos [19], $26.3 \%$ in Ibadan [11], $14.7 \%$ in Irun [6] and $25 \%$ in Abuja [21]. This disparity may be explained by variations among the different study populations with varying exposures to different risk factors based on diverse socio-cultural and geographical differences. This study was conducted among women presenting for cervical cancer screening with many of them being referred by a healthcare worker following complaints of symptoms suggestive of either genital tract 


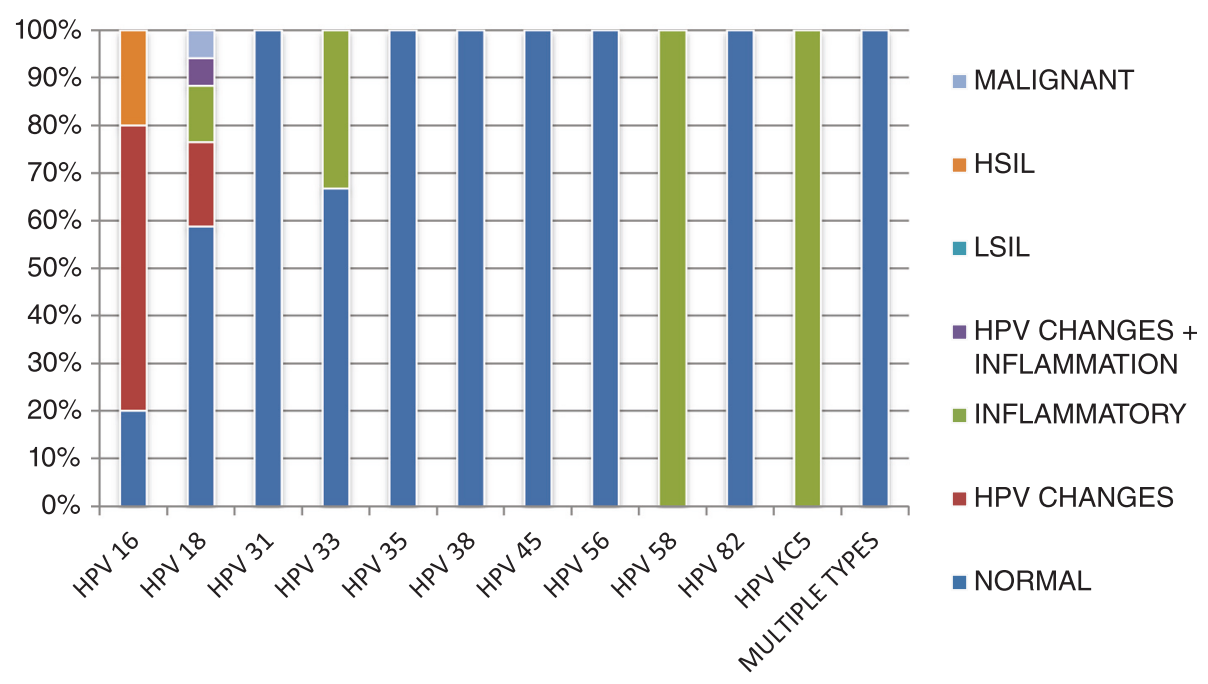

Fig. 1 Percentage distribution of different cytological findings in comparison with corresponding HPV types. HPV types 31, 35, 38, 45, 56, 82 and multiple infections were only present in women with normal cytological findings. HPV 58 and KC5 were only found among women with inflammatory cytological findings. HPV 16 had $20 \%$ normal, 60 \% HPV changes and 20 \% HSIL. HPV 18 had $58.8 \%$ normal, $17.6 \%$ HPV changes, $11.8 \%$ inflammatory, $5.9 \%$ malignant and $5.9 \%$ HPV changes with inflammation. HPV 33 had $66.6 \%$ normal and $33.3 \%$ inflammatory

infection or cervical cancer. Hence, they are naturally a selected "high risk" group for HPV infection. There is widespread polygamy and early marriage [13], with cervical cancer being the commonest genital tract malignancy in this poorest region of the country [12, 14]. Early pregnancy and high parity are all very common in North-Eastern Nigeria [22]. These and probably other unreported risk factors in the locality could be responsible for the high prevalence of HPV infection in this "high risk region".

Studies done in other parts of sub-Saharan Africa among similar population groups have shown similarly high prevalence rates when compared to the value in this study. A prevalence of $66.1 \%$ had been reported among high risk women in Burkina faso [23] while $49.6 \%$ and $60.7 \%$ were also reported among women in Kenya and Sudan respectively [24, 25]. In contrast, some non-African countries showed lower prevalence even among similar population groups with $5.5 \%$ in Iran [26], and $23.6 \%$ in China [27]. This has further buttressed the fact that sub-Saharan Africa, particularly Nigeria carries one of the highest burden of HPV infection in the world $[7,11]$. The predominance of most positive risk factors for HPV alongside inadequate knowledge and awareness about this virus in Africa could be an explanation for the higher prevalence of the infection in this continent. Moreover, from evolutionary point of view, there are predictions that the root of some if not all HPV types could be traced to Africa [28].

The predominance of HPV types 16 and 18 as observed in this study follows the global trend and is in conformity with some Nigerian studies $[11,18]$. However, the observed predominance of HPV 18 as against type 16 in this study is in concert with a similar study from Kano in Northern Nigeria [18]. This suggests the possibility of Northern Nigeria harbouring a higher prevalence of HPV 18 than 16 in contrast to the general global trend. Although very few studies are available to justify this assertion, geographical differences associated with HPV type distribution had been previously reported from other parts of the world [29]. Variations were particularly observed in predominance between the other HPV types found in this study in comparison to most other Nigerian studies from southern part of the country $[10,11,19]$. The predominant HPV types were also different from those reported in Abuja (North-central Nigeria) [21]. This may be attributable to geographical variations in addition to culture and other life styles or partly because most of the studies restricted their search to specific HPV types while this study had the advantage of using DNA sequencing to detect wider variety.

Seven (HPV types 16, 18, 31, 33, 35, 45 \& 58) out of the eight (HPV types 16, 18, 31, 33, 35, 45, 52 and 58) global most common cervical HPV types among women were also found in this study [30]. The five HPV types $(16,18,31,33$ and 45$)$ responsible for $80 \%$ of cancers [31] are also about the most predominant in this study accounting for $13.2 \%, 44.7 \%, 5.3 \%, 7.9 \%$ and $2.6 \%$ for HPVs 16, 18, 31, 33 and 45 respectively. This may probably have contributed to the higher prevalence of cervical cancer in Northern Nigeria [14]. HPV- KC5 has been reported to be present in the normal skin among some rural dwellers in China [32]. More recently, it was also found in the respiratory tract suggesting the possibility of its presence in some other parts of the body 
Table 2 Association between some risk factors and HPV infection

\begin{tabular}{|c|c|c|c|c|c|}
\hline \multirow{2}{*}{$\begin{array}{l}\text { Variable } \\
\text { Age at sexual debut }\end{array}$} & \multicolumn{2}{|c|}{ Presence of HPV DNA } & \multirow[t]{2}{*}{ Total } & \multirow[t]{2}{*}{$x^{2}$} & \multirow[t]{2}{*}{$P$ value } \\
\hline & Positive & Negative & & & \\
\hline & $N(\%)$ & $N(\%)$ & & & \\
\hline$<18$ years & $41(61.2 \%)$ & $26(38.8 \%)$ & $67(100 \%)$ & 6.916 & $0.009^{*}$ \\
\hline$\geq 18$ years & $57(41.6 \%)$ & $80(58.4 \%)$ & $137(100 \%)$ & & \\
\hline \multicolumn{6}{|l|}{ Lifetime sexual partners } \\
\hline Single & $71(43.3 \%)$ & $93(56.7 \%)$ & $164(100 \%)$ & 7.805 & $0.005^{*}$ \\
\hline Multiple & $26(68.4 \%)$ & $12(31.6 \%)$ & $38(100 \%)$ & & \\
\hline \multicolumn{6}{|l|}{ Age at primigravidity } \\
\hline$<18$ years & $24(75.0 \%)$ & $08(25.0 \%)$ & $32(100 \%)$ & 10.554 & $0.005^{*}$ \\
\hline $18-28$ years & $69(43.7 \%)$ & $89(56.3 \%)$ & $158(100 \%)$ & & \\
\hline$>28$ years & $03(42.9 \%)$ & $04(57.1 \%)$ & 07 (100 \%) & & \\
\hline \multicolumn{6}{|l|}{ Parity } \\
\hline Nulliparous & $06(54.5 \%)$ & $05(45.5 \%)$ & $11(100 \%)$ & 23.767 & $<0.001^{*}$ \\
\hline Primiparous & 02 (15.4\%) & $11(84.6 \%)$ & $13(100 \%)$ & & \\
\hline Multiparous & $32(35.6 \%)$ & $58(64.4 \%)$ & $90(100 \%)$ & & \\
\hline Grand multiparous & $48(62.3 \%)$ & $29(37.7 \%)$ & $77(100 \%)$ & & \\
\hline Great-grand multiparous & $12(80.0 \%)$ & $03(20.0 \%)$ & $15(100 \%)$ & & \\
\hline \multicolumn{6}{|l|}{ Presence of co-wives } \\
\hline No other wife & $59(46.1 \%)$ & $69(53.9 .7 \%)$ & $128(100 \%)$ & 1.517 & 0.468 \\
\hline One other wife & $20(50.0 \%)$ & $20(50.0 \%)$ & $40(100 \%)$ & & \\
\hline$\geq 2$ other wives & $17(58.6 \%)$ & $12(41.4 \%)$ & $29(100 \%)$ & & \\
\hline \multicolumn{6}{|c|}{ Family history of cervical cancer } \\
\hline No & $85(47.0 \%)$ & $96(53.0 \%)$ & $181(100 \%)$ & 0.719 & 0.397 \\
\hline Yes & $14(56.0 \%)$ & $11(44.9 \%)$ & $25(100 \%)$ & & \\
\hline \multicolumn{6}{|l|}{ History of other malignancies } \\
\hline No & $80(44.7 \%)$ & $99(55.3 \%)$ & $53(100 \%)$ & 7.325 & $0.007^{*}$ \\
\hline Yes & $19(73.1 \%)$ & $07(26.9 \%)$ & $26(100 \%)$ & & \\
\hline \multicolumn{6}{|l|}{ Type of other malignancies } \\
\hline Gynaecological & 17 (73.9 \%) & 06 (26.1\%) & $23(100 \%)$ & 0.522 & 0.470 \\
\hline Others & $01(50.0 \%)$ & $01(50.0 \%)$ & $02(100 \%)$ & & \\
\hline \multicolumn{6}{|l|}{ HIV Status } \\
\hline Positive & $07(63.6 \%)$ & $04(36.4 \%)$ & $11(100 \%)$ & & $0.222^{* *}$ \\
\hline Negative & $47(43.5 \%)$ & $61(56.5 \%)$ & $108(100 \%)$ & & \\
\hline \multicolumn{6}{|l|}{ Hormonal contraceptives } \\
\hline No & $50(45.0 \%)$ & $61(55.0 \%)$ & $111(100 \%)$ & 0.874 & 0.350 \\
\hline Yes & $48(51.6 \%)$ & $45(48.4 \%)$ & $93(100 \%)$ & & \\
\hline \multicolumn{6}{|l|}{ Use of condom } \\
\hline No & $73(50.3 \%)$ & $72(49.7 \%)$ & $145(100 \%)$ & 1.026 & 0.311 \\
\hline Yes & $26(42.6 \%)$ & $35(57.4 \%)$ & $61(100 \%)$ & & \\
\hline
\end{tabular}

** $=$ Fischer's exact test

* $=$ statistically significant (i.e. $<0.05$ )

[33]. HPV-KC5 may not confer a risk for cervical cancer as it does not belong to alpha HPV species which contain all the types responsible for cervical cancer [3].
Low prevalence of multiple HPV infections as observed in this study compared to studies that used type specific primers (TS-PCR) in genotyping is not unusual 
Table 3 Logistic regression analysis of some risk factors for HPV infection

\begin{tabular}{|c|c|c|c|c|}
\hline & Regression Coefficient & $P$-value & Odds ratio & $95 \% \mathrm{Cl}$ \\
\hline \multicolumn{5}{|l|}{ Level of education } \\
\hline No formal education (REF) & & & 1.000 & \\
\hline Primary & 0.818 & 0.301 & 2.267 & $0.481-10.680$ \\
\hline Secondary & -0.223 & 0.809 & 0.800 & $0.131-4.874$ \\
\hline OND/NCE/HND & 0.811 & 0.286 & 2.250 & $0.507-9.993$ \\
\hline University graduate & 2.219 & $0.010^{*}$ & 9.200 & $1.698-49.858$ \\
\hline Others & 0.501 & 0.502 & 1.650 & $0.383-7.109$ \\
\hline \multicolumn{5}{|l|}{ Age at sexual debut } \\
\hline$\geq 18$ years (REF) & & & 1.000 & \\
\hline$<18$ years & -0.794 & $0.009^{*}$ & 0.452 & $0.249-0.821$ \\
\hline \multicolumn{5}{|l|}{ Parity } \\
\hline Nulliparous (REF) & & & 1.000 & \\
\hline primiparous & 1.204 & 0.174 & 3.333 & $0.588-18.891$ \\
\hline Multiparous & 3.091 & $0.002^{*}$ & 22.000 & $3.076-157.341$ \\
\hline Grandmultiparous & 1.981 & $0.004^{*}$ & 7.250 & $1.905-27.598$ \\
\hline Great-grand multiparous & 0.882 & 0.199 & 2.417 & $0.629-9.290$ \\
\hline \multicolumn{5}{|l|}{ Sexual partner (s) } \\
\hline Single (REF) & & & 1.000 & \\
\hline Multiple & 1.043 & $0.006^{*}$ & 2.838 & $1.340-6.011$ \\
\hline \multicolumn{5}{|l|}{ Age at primigravidity } \\
\hline 18-28 years (REF) & & & 1.000 & \\
\hline$<18$ years & -1.386 & 0.109 & 0.250 & $0.046-1.365$ \\
\hline$>28$ years & -0.033 & 0.966 & 0.967 & $0.210-4.466$ \\
\hline \multicolumn{5}{|l|}{ History of other malignancies } \\
\hline No (REF) & & & 1.000 & \\
\hline Yes & 0.363 & 0.398 & 1.437 & $0.619-3.336$ \\
\hline
\end{tabular}

* $=$ Statistically significant (i.e. $<0.05)$

REF Reference Category, OND Ordinary National Diploma, HND Higher National Diploma, NCE National Certificate of Education

[18]. Sequencing has however been shown to detect more genotypes than TS-PCR suggesting the need to combine both methods for maximum yield [34]. This study utilized nested PCR using PGMY 09/11 and GP5+/GP6+ which has been shown to be sensitive in detecting wider range of HPV genotypes and also relatively more effective in detecting multiple infections[35]. However, the inability of this study to detect low risk HPV genotypes may be attributable the PGMY 09/11 primer which has low capacity of detecting lr-HPV and the fact they are generally fewer in cervical specimens and also more common among males than females [35-37].

Several variables (level of education, age at sexual debut, age at first pregnancy, parity, lifetime sexual partners and history of other malignancies) observed in this study revealed a statistically significant association with HPV infection. Low socio-economic status, early marriage/coitarche, polygamy and high parity are all wellestablished risk factors for HPV infection [7, 38].
Women with lower levels of education were found to have a higher risk of HPV infection as shown in this study and another Nigerian study [21]. Higher educational level among women is generally associated with increased knowledge/attitude towards HPV and its preventive measures with minimal risk factors for the infection[39]. This has also been observed in this study as many of participants were highly educated up to tertiary level as against the corresponding $2 \%$ among the general female population in the area[12]. Therefore, this study may not depict the true picture of the general population. A study among cervical cancer screening population group in Lagos, Nigeria also reaffirmed the statistical significance of age at sexual debut, parity and lifetime sexual partners as risk factors for HPV infection [20]. In contrast to this study, Adegbesan-Omilabu et al., and Rocha-Brischiliari et al. all reported the use of oral contraceptive pills, HIV infection and cigarette smoking as significant risk factors for HPV infection [2, 40]. This 
may be attributed to the relatively few percentage of women that responded to questions on smoking history $(0.5 \%)$, use of hormonal contraception $(44.5 \%)$ and HIV infection (5.2\%). Possible variations in the duration of exposure to these factors among different studied populations may also be contributory. Women with longer duration of exposure to oral contraceptives have been shown to have 2-fold increase in risk of acquiring HPV infection [41]. In concert with this study, marital status, presence of co-wives, religion and tribe were all not statistically significant risk factors for HPV as highlighted by some Nigerian studies [20]. Also unrelated to the risk of HPV infection in this study is the use of condom as has also been observed in Ibadan by Thomas et al. [10].

Majority of the studied population fell within the age group 30 to 45 years, hence are suitable for enrolment in screening and treatment programmes in preventing cervical cancer [6]. In addition, up to 166 (79.8 \%) of the participants in this study were above 30 years of age which shows that majority may be having a persistent HPV infection (the actual risk for developing cervical cancer). This finding further reaffirms the suitability of HPV DNA detection as an important diagnostic tool for cervical cancer screening in this population [42].

Logistic regression analysis of the identified risk factors showed that university education, multiple sexual partners, multiparity and grand multiparity are associated with a significantly increased likelihood of having HPV infection among the participants. The apparent significance of university education as a risk factor against our earlier observation and the general trend may not be unconnected with skewed distribution of the respondents in terms of educational qualification. These findings further confirm the need for a larger and community based study to obviate the lopsided distribution of the participants as majority of them are educated and screening is mostly based on referral by healthcare workers.

\section{Conclusion}

HPV Prevalence of $48.1 \%$ was recorded from this study. Eleven different HPV types were detected with the five most predominant types (sequentially) being 18, 16, 33, 31 and 35 . Other types were $38,45,56,58,82$ and KC5. Low level of education, early age at sexual debut, high parity, multiple life time sexual partners, early age at first pregnancy and positive history of other malignancies were the significant risk factors associated with cervical HPV infection in Gombe.

This study has revealed north-eastern Nigeria as having one of the highest HPV prevalence in the country and also a region that will benefit from the currently available HPV vaccines.
There is need for a universal, well-coordinated, multicentred, rural and urban community based study on HPV in addition to a comprehensive national cervical cancer screening programme and improved availability/ accessibility of the currently available HPV vaccines in all parts of Nigeria.

\section{Additional file}

Additional file 1: Detailed Methodology. (DOCX $21 \mathrm{~kb})$

\section{Abbreviations}

$\mathrm{Cl}$ : Confidence interval; CIN: Cervical intraepithelial neoplasia; FTHG: Federal Teaching Hospital Gombe; HPV: Human papillomavirus; hr: High risk; Ir: Low risk; ICC: Invasive cervical cancer; OR: Odds ratio; PCR: Polymerase chain reaction.

\section{Competing interests}

The authors declare that they have no competing interests.

\section{Authors' contributions}

$M M, A F, R A \& A U$ conceived the study and drafted the manuscript. $A U$ \& $Y M$ were responsible for specimens and data acquisition. AD performed statistical analysis. MM, AF \& YM were responsible for all laboratory analyses. $A O, R A \& H U$ participated in the design and coordination of the study. All authors contributed to data interpretation, read and approved the final manuscript.

\section{Acknowledgements}

The authors wish to acknowledge other members of staff of the gynaecology/cytology clinics of FTHG and the DNA Labs Kaduna Nigeria for their contributions in specimen collection and processing. We also appreciate the inputs from Dr KC Iregbu and Prof AO Aboderin.

\section{Author details}

'Department of Medical Microbiology and Immunology, Federal Teaching Hospital Gombe, Gombe, Gombe state Nigeria. ${ }^{2}$ Department of Medical Microbiology and Parasitology, University College Hospital Ibadan, Ibadan, Oyo state Nigeria. ${ }^{3}$ Department of Histopathology, Federal Teaching Hospital Gombe, Gombe, Gombe state Nigeria. ${ }^{4}$ Department of Obstetrics and Gynaecology, Federal Teaching Hospital Gombe, Gombe, Gombe state Nigeria. ${ }^{5}$ Department of Radiotherapy and Oncology, Federal Teaching Hospital Gombe, Gombe, Gombe state Nigeria.

Received: 24 March 2015 Accepted: 23 September 2015

Published online: 02 October 2015

\section{References}

1. Schiffman M, Castle PE, Jeronimo J, Rodriguez AC, Wacholder S. Human papillomavirus and cervical cancer. The Lancet. 2007;370:890-907.

2. McLaughlin-Drubin ME, Munger K. Viruses Associated with Human Cancer. Biochim Biophys Acta. 2008;1782:127-50.

3. IARC Monographs on the evaulation of carcinogenic risks to humans. 2012 http://monographs.iarc.fr/ENG/Monographs/vol100B/mono100B.pdf (Accessed 9/7/2014)

4. Wheeler CM, Castellsagué X, Garland SM, Szarewski A, Paavonen J, Naud P, et al. Cross-protective efficacy of HPV-16/18 AS04-adjuvanted vaccine against cervical infection and precancer caused by non-vaccine oncogenic HPV types: 4-year end-of-study analysis of the randomised, double-blind PATRICIA trial. Lancet Oncol. 2012;13:100-10.

5. Veldhuijzen NJ, Snijders PJ, Reiss P, Meijer CJ, van de Wijgert JH. Factors affecting transmission of mucosal human papillomavirus. Lancet Infect Dis. 2010;10:862-74.

6. Gage JC, Ajenifuja KO, Wentzensen NA, Adepiti AC, Eklund C, Reilly M, et al. The age-specific prevalence of human papillomavirus and risk of cytologic abnormalities in rural Nigeria: Implications for screen-and-treat strategies. Int J Cancer J Int Cancer. 2012;130:2111-7.

7. Anorlu RI. Cervical cancer: the sub-Saharan African perspective. Reprod Health Matters. 2008;16:41-9. 
8. Awodele O, Adeyomoye AAA, Awodele DF, Kwashi V, Awodele IO, Dolapo DC. A Study on Cervical Cancer Screening Amongst Nurses in Lagos University Teaching Hospital, Lagos, Nigeria. J Cancer Educ. 2011;26:497-504.

9. Becker-Dreps S, Otieno WA, Brewer NT, Agot K, Smith JS. HPV vaccine acceptability among Kenyan women. Vaccine. 2010;28:4864-7.

10. Thomas JO, Herrero R, Omigbodun AA, Ojemakinde K, Ajayi IO, Fawole A, et al. Prevalence of papillomavirus infection in women in Ibadan, Nigeria: a population-based study. Br J Cancer. 2004;90:638-45.

11. Okolo C, Franceschi S, Adewole I, Thomas JO, Follen M, Snijders PJ, et al. Human papillomavirus infection in women with and without cervical cancer in Ibadan, Nigeria. Infect Agent Cancer. 2010;5:24.

12. Nigeria Demographic and Health Survey 2013 [FR293] - FR293.pdf. http:// dhsprogram.com/pubs/pdf/FR293/FR293.pdf (Accessed on 17/07/2015)

13. Ajuwon AJ, Olaleye A, Faromoju B, Ladipo O. Sexual behavior and experience of sexual coercion among secondary school students in three states in North Eastern Nigeria. BMC Public Health. 2006:6:310.

14. Kyari $\mathrm{O}$, Nggada $\mathrm{H}$, Mairiga A. Malignant tumours of female genital tract in North Eastern Nigeria. East Afr Med J. 2004;81:142-5.

15. Audu BM, Bukar M, Ibrahim Al, Swende TZ. Awareness and perception of human papilloma virus vaccine among healthcare professionals in Nigeria. J Obstet Gynaecol. 2014;34:714-7.

16. Evans MF, Adamson CS, Simmons-Arnold L, Cooper K. Touchdown General Primer (GP5+/GP6+) PCR and optimized sample DNA concentration support the sensitive detection of human papillomavirus. BMC Clin Pathol. 2005;5:10.

17. Gravitt PE, Peyton CL, Alessi TQ, Wheeler CM, Coutlée F, Hildesheim A, et al. Improved Amplification of Genital Human Papillomaviruses. J Clin Microbiol. 2000;38:357-61.

18. Auwal IK, Aminu M, Atanda AT, Tukur J, Sarkinfada F. Prevalence and Risk Factors of High Risk Human Papillomavirus Infections among Women Attending Gynaecology Clinics in Kano, Northern Nigeria. Bayero J Pure Appl Sci. 2014;6:67-71.

19. Ezechi OC, Ostergren PO, Nwaokorie FO, Ujah IA, Pettersson KO. The burden, distribution and risk factors for cervical oncogenic human papilloma virus infection in HIV positive Nigerian women. Virol J. 2014;11:5.

20. AdegbesanOmilabu M, Okunade K, Omilabu S. Oncogenic human papilloma virus infection among women attending the cytology clinic of a tertiary hospital in Lagos, South-West Nigeria. Int J Res Med Sci. 2014;2:625.

21. Akarolo-Anthony SN, Al-Mujtaba M, Famooto AO, Dareng EO, Olaniyan OB, Offiong $\mathrm{R}$, et al. HIV associated high-risk HPV infection among Nigerian women. BMC Infect Dis. 2013:13:521.

22. National Population Commission (NPC) [Nigeria] and ICF International. 2014. Nigeria Demographic and Health Survey 2013. Abuja, Nigeria, and Rockville, Maryland, USA: NPC and ICF International.

23. Didelot-Rousseau M-N, Nagot N, Costes-Martineau V, Vallès X, Ouedraogo A, Konate I, et al. Human papillomavirus genotype distribution and cervical squamous intraepithelial lesions among high-risk women with and without HIV-1 infection in Burkina Faso. Br J Cancer. 2006;95:355-62.

24. De Vuyst H, Steyaert S, Van Renterghem L, Claeys P, Muchiri L, Sitati S, et al. Distribution of Human Papillomavirus in a Family Planning Population in Nairobi, Kenya. Sex Transm Dis. 2003;30:137-42.

25. Salih MM, Safi ME, Hart K, Tobi K, Adam I. Genotypes of human papilloma virus in Sudanese women with cervical pathology. Infect Agent Cancer. 2010;5:26.

26. Zandi K, Eghbali SS, Hamkar R, Ahmadi S, Ramedani E, Deilami I, et al. Prevalence of various Human Papillomavirus (HPV) genotypes among women who subjected to routine Pap smear test in Bushehr city (South west of Iran) 2008-2009. Virol J. 2010;7:65.

27. Zhao F-H, Forman MR, Belinson J, Shen Y, Graubard BI, Patel AC, et al. Risk factors for HPV infection and cervical cancer among unscreened women in a high-risk rural area of China. Int J Cancer J Int Cancer. 2006;118:442-8.

28. Ong CK, Chan SY, Campo MS, Fujinaga K, Mavromara-Nazos P, Labropoulou V, et al. Evolution of human papillomavirus type 18: an ancient phylogenetic root in Africa and intratype diversity reflect coevolution with human ethnic groups. J Virol. 1993:67:6424.

29. Orozco-Colín A, Carrillo-García A, Méndez-Tenorio A, Ponce-de-León S, Mohar A, Maldonado-Rodríguez R, et al. Geographical variation in human papillomavirus prevalence in Mexican women with normal cytology. Int J Infect Dis. 2010;14:e1082-7.

30. Bruni L, Diaz M, Castellsagué M, Ferrer E, Bosch FX, de Sanjosé S. Cervical Human Papillomavirus Prevalence in 5 Continents: Meta-Analysis of 1
Million Women with Normal Cytological Findings. J Infect Dis 2010:202:1789-99.

31. Galloway DA. Is vaccination against human papillomavirus a possibility? Lancet. 1998;351 Suppl 3:22-4.

32. Li J, Cai H, Xu Z, Wang Q, Hang D, Shen N, et al. Nine Complete Genome Sequences of Cutaneous Human Papillomavirus Genotypes Isolated from Healthy Skin of Individuals Living in Rural He Nan Province, China. J Virol. 2012:86:11936-6.

33. Canuti M, Deijs M, Jazaeri Farsani SM, Holwerda M, Jebbink MF, de Vries M, et al. Metagenomic analysis of a sample from a patient with respiratory tract infection reveals the presence of a $\gamma$-papillomavirus. Virology. 2014;5:347.

34. Carvalho Nde O, del Castillo DM, Perone C, Januário JN, Melo VH, Brasileiro Filho G. Comparison of HPV genotyping by type-specific PCR and sequencing. Mem Inst Oswaldo CruZ. 2010;105:73-8.

35. Cai YP, Yang Y, Zhu BL, Li Y, Xia XY, Zhang RF, et al. Comparison of human papillomavirus detection and genotyping with four different prime sets by PCR-sequencing. Biomed Environ Sci BES. 2013;26:40-7.

36. Giorgi Rossi P, Bisanzi S, Paganini I, Di lasi A, Angeloni C, Scalisi A, et al. Prevalence of HPV high and low risk types in cervical samples from the Italian general population: a population based study. BMC Infect Dis. 2010:10:214.

37. Giuliano AR, Tortolero-Luna G, Ferrer E, Burchell AN, de Sanjose S, Kjaer SK, et al. Epidemiology of human papillomavirus infection in men, cancers other than cervical and benign conditions. Vaccine. 2008;26 Suppl 10:K17-28.

38. Vinodhini K, Shanmughapriya S, Das BC, Natarajaseenivasan K. Prevalence and risk factors of HPV infection among women from various provinces of the world. Arch Gynecol Obstet. 2012;285:771-7.

39. Chang IJ, Huang R, He W, Zhang S-K, Wang S-M, Zhao F-H, et al. Effect of an educational intervention on HPV knowledge and vaccine attitudes among urban employed women and female undergraduate students in China: a cross-sectional study. BMC Public Health. 2013;13:916.

40. Rocha-Brischiliari SC, Gimenes F, de Abreu ALP, Irie MM, Souza RP, Santana $R G$, et al. Risk factors for cervical HPV infection and genotypes distribution in HIV-infected South Brazilian women. Infect Agent Cancer. 2014;9:6.

41. Kjaer SK, van den Brule AJ, Bock JE, Poll PA, Engholm G, Sherman ME, et al. Determinants for genital human papillomavirus (HPV) infection in 1000 randomly chosen young Danish women with normal Pap smear: are there different risk profiles for oncogenic and nononcogenic HPV types? Cancer Epidemiol Biomarkers Prev. 1997;6:799-805.

42. Katki HA, Kinney WK, Fetterman B, Lorey T, Poitras NE, Cheung L, et al. Cervical cancer risk for women undergoing concurrent testing for human papillomavirus and cervical cytology: a population-based study in routine clinical practice. Lancet Oncol. 2011;12:663-72.

\section{Submit your next manuscript to BioMed Central and take full advantage of:}

- Convenient online submission

- Thorough peer review

- No space constraints or color figure charges

- Immediate publication on acceptance

- Inclusion in PubMed, CAS, Scopus and Google Scholar

- Research which is freely available for redistribution 